\title{
Necesidad de un geoportal catastral estandarizado, interoperable y usable
}

\author{
María Ester Gonzalez Campos* \\ Rocío Narváez Benalcázar ${ }^{* *}$ \\ Miguel Ángel Bernabé Poveda**
}

Recibido el 2 de enero de 2017; aceptado el 15 de junio de 2017

\begin{abstract}
Both the municipalities and the State Government of Ecuador are in a critical situation regarding the implementation of the Land Registry. On the one hand, the country constitution supports the decentralization of El Ecuador leading to its municipalities have the responsibility of implementing the property registration. On the other hand, the Association of Municipalities of Ecuador (AME) has a nonstandard format for collecting cadastral information which is followed by a good part of the Ecuadorian municipalities; other municipalities are still other formulas, some inadvisable. The lack of land standards recommended by international institutions (ISO, OGC) that facilitate interoperability of geographic information, prevent the crossing of cadastral information with other spatial information of the country, which does not allow place the cadastre map servers able to be accessed ubiquitously. This is dramatic for the country (state institutions, companies and individuals) who are unable to use computer tools for take land decisions on several municipalities, a province or the entire country. In addition to the lack of uniformity of cadastral files, appears the difficulty to store and manage cadastral information based on GIS type complex programs that require the use of specialists (at cost to the municipal coffers) and the lack of usability of query interfaces. This work supports the

* Universidad de Concepción, Juan Antonio Coloma 0201, Los Ángeles, Chile, correo electrónico: mariaesgonzalez@udec.cl

** Instituto Geográfico Militar. Seniergues E4-676 y Gral. Telmo Paz y Miño, El Dorado, Quito, Ecuador, correo electrónico: rocio.narvaez@igm.gob.ec

*** Universidad Politécnica de Madrid, Calle Mercator 1, Madrid, España, correo electrónico: ma.bernabe@upm.es
\end{abstract}


idea of the need for a National Cadastral IDE and designing tools to facilitate the consultations carried out to the IDE.

Key words: Cadastral SDI, Geoportals usability, Virtual Assistant.

\section{Resumo}

Tanto os municípios do Equador como o próprio Estado estão em uma situação crítica relacionada à atualização do Cadastro. A Constituição apoia a descentralização do Estado, o que leva os municípios a assumir a total responsabilidade pela implementação dos cadastros. A Associação dos Municípios do Equador (AME), tem um formato não padronizado para a coleta de informações cadastrais, que é seguida por boa parte dos municípios equatorianos; entretanto os demais municípios seguem outras fórmulas, algumas delas não interoperáveis. A falta de aplicação das normas recomendadas para o cadastro pelas instituições internacionais (ISO, OGC), que facilitam a interoperabilidade da informação geográfica, dificultam o cruzamento da informação cadastral com o restante da informação territorial disponível, o que não permite colocar o cadastro em servidores de mapas do tipo WMS capazes de consultas simultâneas. Isso é dramático para o país (instituições do estado, empresas e indivíduos) que não têm a possibilidade de usar as ferramentas digitais para a tomada de decisão territorial conjunta nos diferentes níveis de governo ou sobre o território nacional. Além dessa falta de uniformidade dos arquivos cadastrais existe a dificuldade de armazenar e gerenciar informações cadastrais, utilizando programas complexos do tipo SIG que exigem a participação de especialistas encarregados das finanças municipais e a falta de usabilidade das interfaces de consulta. Este artigo apresenta a ideia de que existe uma IDE cadastral nacional, padronizada, interoperável e utilizável que possui ferramentas que facilitam a consulta dos diferentes usuários.

Palavras-chave: IDE cadastral, Usabilidade de Geoportais, Assistentes virtuais.

\section{Resumen}

Tanto los municipios de Ecuador como el propio Estado se encuentran en una situación crítica relacionada con la actualización del Catastro. Por un lado, la Constitución apoya la descentralización del Estado, lo que conduce a que los municipios tengan la total responsabilidad de la puesta en marcha de los catastros. Por otro lado, la Asociación de Municipios del Ecuador (AME), dispone de un formato no estandarizado para la recogida de información catastral, que sigue una buena parte de los municipios ecuatorianos; otros municipios siguen otras fórmulas, algunas de ellas nada interoperables. La falta de aplicación de los estándares recomendados para el catastro por las instituciones internacionales (ISO, OGC), que facilitan la interoperabilidad de la información geográfica, dificulta el cruce de la información catastral 
con el resto de la información territorial disponible, lo cual no permite situar el catastro en servidores de mapas tipo WMS capaces de ser consultados de forma ubicua. Esto es dramático para el país (instituciones estatales, empresas y particulares) que no tienen posibilidad de utilizar las herramientas informáticas para la toma conjunta de decisiones territoriales en los diferentes niveles de gobierno o sobre todo el territorio nacional. Adicional a esta falta de uniformidad de los archivos catastrales está la dificultad para almacenar y gestionar la información catastral, con el uso de complejos programas tipo SIG que exigen el concurso de especialistas con cargo a las arcas municipales y con la falta de usabilidad de los interfaces de consulta. El presente trabajo presenta la idea de que exista una IDE catastral nacional, estandarizada, interoperable y usable que disponga de herramientas que faciliten la consulta de los distintos usuarios de la misma.

Palabras clave: IDE Catastral, Usabilidad de Geoportales, asistentes virtuales.

\section{Introducción}

Los cambios en el ámbito territorial motivados por las elecciones de noviembre de 2006 en la República de Ecuador se cristalizaron en octubre de 2010 cuando el Código Orgánico de Organización Territorial, Autonomía y Descentralización (COOTAD), alcanzó la categoría de Ley de la República. Esta Ley venía a refrendar el objetivo político de que Ecuador fuera un gobierno descentralizado como se establecía en el artículo primero de la Constitución del 2008. Los diferentes niveles de gobierno del Estado se denominaron Gobiernos Autónomos Descentralizados (GAD) repartiéndose el territorio nacional en 4 GAD Regionales, 24 Provinciales, 221 Cantonales y 1217 Parroquiales (804 rurales) (INEC, 2010). Como en otros países de la región (Venezuela, Perú, Brasil, El Salvador), el catastro es administrado descentralizadamente (DataCatastro, 2011).

El catastro, al ser por antonomasia un inventario, es la base de datos fundamental de la información territorial de cada GAD, que además de la función casi exclusivamente fiscal que tiene en Ecuador (Erba, 2008), puede servir como soporte para la toma de decisiones sobre el territorio. La información que se obtiene se refiere a las características de los predios, en sus componentes métricas de terreno y de construcción, sus propietarios y la forma de tenencia; posteriormente en el ámbito fiscal, es el soporte para la valoración de la propiedad, que finalmente se utiliza para el cálculo del impuesto predial.

El Gobierno ecuatoriano persigue que la autonomía de los GAD sea efectiva y cada uno de ellos pueda ser realmente autónomo generando sus propios recursos. El catastro, además de las ventajas que supone conocer la distribución, ubicación, medidas y aprovechamiento de los terrenos y las construcciones, es una de las maneras más efectivas de recolectar impuestos de una forma equitativa. Gracias a esa recaudación, los GAD podrían enfrentarse a sus necesidades sin tener que esperar 
mayores subvenciones o ayudas del gobierno central para emprenderlas. El Gobierno ha fomentado estas iniciativas hasta el punto de hacerlas obligatorias y para tal fin ha puesto los medios para que cada GAD disponga de las herramientas tecnológicas para llevar a cabo su catastro. También la Asociación de Municipios de Ecuador (AME), dinamiza por medio de un modelo de datos la homogeneización de los mismos. Sin embargo, debido a:

- la libertad que tiene cada GAD para utilizar el sistema que le parezca más oportuno para realizar su propio catastro;

- la falta de formación del personal de los GAD para la gestión territorial del catastro;

- la falta de utilización generalizada de estándares internacionales tipo ISO 19152;

- la ausencia de un sistema de gestión catastral integrado con otras áreas del propio GAD, con otros GAD del mismo nivel y de niveles superiores;

- la deficiente usabilidad del interfaz del sistema catastral (cuando existe) que separa el catastro rural del urbano, impidiendo los análisis integrales; y

- la imposibilidad de acceder a la información catastral a través de Internet, hacen que la capa catastral no pueda compartirse con otras capas geográficas limitando así las capacidades de toma de decisión de forma instantánea sobre el territorio.

La puesta en marcha de una Infraestructura de Datos Catastrales de cobertura nacional, con un geoportal en la nube dotado de un grado máximo de usabilidad que permita la carga de datos, la actualización, la gestión y las consultas desde cualquier $\mathrm{GAD}$, con los permisos que cada usuario disponga, es un objetivo que el país tiene en su horizonte cercano. Y para que cualquier responsable de los GAD, al margen de su formación en base de datos, pudiera realizar consultas al sistema, éste debería tener implementado un interfaz de comunicación con el usuario, ya sea vía voz o vía texto, dotado de semántica, que respondiera preguntas sencillas realizadas en lenguaje natural sin necesidad de utilizar la comunicación propia de los SIG.

Exponemos el caso de Ecuador, pero creemos que el problema de la incorporación de la capa catastral a sistemas interoperables capaces de compartir esta información con otras capas de información geográfica es de interés para otros países o regiones de Latinoamérica.

En este trabajo se presenta en primer lugar el panorama general de la información geográfica y la situación del catastro en Ecuador. A partir de estos antecedentes se presenta la propuesta de una IDE Catastral o Infraestructura Nacional de Datos Catastrales que dé respuesta a las problemáticas en materia de catastro que se presentan en el país. Se detallan a continuación una serie de características que se deberían considerar en la implementación de esta IDE Catastral. Finalmente se presentan unas breves conclusiones. 


\section{Situación de la información geográfica en Ecuador}

En la última década, el gobierno central ha realizado inversiones millonarias en la generación de información geográfica (IG) del país, potenciando además la Infraestructura Ecuatoriana de Datos Espaciales (IDE). La IDE de un país es un sistema informático que permite acceder de manera ubicua a su IG. Esta IG, proveniente de instituciones oficiales, se pone a disposición de los ciudadanos en espacios web que permiten como mínimo las cuatro operaciones que deben estar presentes en los geoportales: (a) visualización de mapas, (b) localización de datos y servicios, (c) descarga de conjuntos de datos y (d) procesamiento de los datos (INSPIRE, 2007/02/EC). Esa IDE, basada en estándares ISO, proporciona la deseada interoperabilidad de datos y servicios, de manera que pueden, a través de Internet, ponerse una sobre otra las capas de información de cualquier institución del país, coincidiendo métricamente las mismas y posibilitando el análisis de las consecuencias de una decisión territorial sobre la realidad que representan esas capas.

En Ecuador, la Secretaría Nacional de Planificación y Desarrollo (SENPLADES) ha tomado la responsabilidad política y técnica de hacer que todos los datos del país estén disponibles a través de la página web del Sistema Nacional de Información $<$ http://app.sni.gob.ec/sni/>. Las ventajas de una IDE son enormes y por no citar más que las principales diremos que si se dispone de IDE:

- La IG del país estará homogeneizada en base a metadatos estandarizados.

- Las capas de información no estarán duplicadas en distintas instituciones, sino que se mantienen y actualizan por la institución que es responsable en el país.

- Toda la información será accesible a través de Internet con diferentes permisos de acceso, siendo el permiso de visualización el más elemental, pero pudiéndose llegar a descargar los archivos que el usuario necesite.

- Se accede a toda la información del país a través de un geoportal único, desde el que se llega tanto a los geoportales temáticos (hidrografía, usos del suelo, población, etc.) como a los geoportales administrativos (provincia, municipio, parroquia).

- Con las capas necesarias a la vista, se pueden tomar decisiones territoriales en cualquiera de los niveles administrativos.

Si la IG de un país (o de una institución del país) no es conforme con los estándares internacionales que permiten poner en marcha una IDE, existirán limitaciones a la hora de tomar decisiones y de reutilizar la misma, lo cual es una pérdida para el país considerando lo costosa que es dicha IG. Eso es lo que pasa con la información catastral de Ecuador, donde cerca del 90\% de los municipios tienen información catastral alfanumérica, pero menos del 25\% la tienen georreferenciada (Rodríguez, 2012b). 


\section{Situación del catastro ecuatoriano}

Asociada a la descentralización, la autonomía financiera de los GAD, estaría basada en sus ingresos propios, en las transferencias y en su financiamiento. Los ingresos propios tributarios (como los impuestos, las tasas y las contribuciones) han tenido en los catastros (rural y urbano) una herramienta tradicional distributiva en la mayoría de los países. La existencia y actualización de los catastros sería pues para los municipios una de las formas de potenciar su autonomía. Aunque en Latinoamérica los ingresos por impuestos prediales no pasan del $0.5 \%$ del PIB, en países como Estados Unidos, Reino Unido o Canadá representan el 2.5\% de su PIB.

El fortalecimiento del catastro en Ecuador tiene especial relevancia para cumplir con los objetivos del Plan Nacional del Buen Vivir (PNBV), en especial en lo relativo a los objetivos de la erradicación de la pobreza, a combatir las desigualdades territoriales, a dotar servicios e infraestructura pública de calidad en los territorios, a lograr adecuados procesos de planificación y ordenamiento territorial, así como de regulación y control del uso del suelo. El PNBV establece con absoluta relevancia el rol estratégico y vital de los GAD para que, a través de un efectivo ejercicio de sus competencias, impulsen la equidad territorial.

En la actualidad, en Ecuador las tareas catastrales corresponden a los GAD Municipales a los que expresamente el Artículo 32 del COOTAD les proporciona competencias para "planificar, junto con otras instituciones del sector público, el desarrollo regional y formular los correspondientes planes de ordenamiento territorial”. El Catastro, base de información, es visto como fuente de financiación tradicional, que pasó a ser gestionada por los GAD Municipales, tanto en áreas urbanas como en rurales. Para apoyar esta labor, el gobierno a través del Proyecto SIGTIERRAS <www.sigtierras.gob.ec/> decide, entre otras medidas, dotar a los GAD de una infraestructura informática compuesta de hardware, un Sistema de Información Geográfica (SIG) y la ortofoto del municipio, con el fin de que sirva de base para la gestión del catastro. Sin embargo, en algunos casos, los equipos llegaron a los municipios, pero no fueron explotados adecuadamente, dada la complejidad de su instalación, la dificultad de manejo, y la carga de trabajo para adaptar los archivos catastrales existentes y en uso, pues no existe en una mayoría de los municipios personal especializado en el uso de SIG. La AME, uno de cuyos objetivos es fortalecer las capacidades de los GAD, potencia su propio modelo catastral denominado Sistema Integral de Catastros, que permite que los municipios almacenen y procesen la información de los predios urbanos y rurales. Sin embargo, esta iniciativa no se realiza siguiendo los estándares de interoperabilidad recomendados por las organizaciones internacionales (ISO, OGC, GEOSUR, GDSI) ni se integran los estándares catastrales recomendados por la ISO 19152 (Land Administration Domain Model). A pesar de los esfuerzos de la AME para que se incorporen las herramientas SIG a las labores catastrales municipales, las cifras indican que solo el $10 \%$ de los muni- 
cipios utilizan esta tecnología (Reyes Bueno et al., 2012). Esto hace muy difícil pensar que la información catastral de los municipios de Ecuador va a estar informatizada en un breve espacio de tiempo y mucho menos disponible a través de la web. Esta situación se contrapone con los deseos del gobierno estatal que dispone e impulsa sistemas que permiten compartir la información y hacer que ésta sea accesible a través de Internet. También dificulta a las empresas públicas, el uso de la información catastral, a pesar de que ésta podría utilizarse no solamente para cuestiones fiscales sino también para usos agrarios, de gestión de las infraestructuras, para la planificación urbana, para el mercado inmobiliario, etc., (Rodríguez, 2012a). El hecho de que pequeños municipios tengan su catastro en formatos y medios propios carentes de estándares, no facilita el reúso de su información. Existen iniciativas (Trinidad, 2011) como respuesta a este problema de pequeños ayuntamientos para homogeneizar la información catastral dentro de estándares ISO. Esa solución, sin conectividad a Internet no resuelve el segundo problema encontrado, que es el de compartir la información, no solo con otras dependencias municipales sino con otras instituciones a todos los niveles (notarías, registros de la propiedad, otros GAD, ministerios e instituciones, etc.).

Se puede resumir la situación catastral media del país diciendo que (Rodríguez, 2012a):

- La elaboración y administración de los catastros inmobiliarios de cada GAD depende de él mismo

- El Gobierno apoya decididamente la creación de los catastros

- No existe un modelo común para todos los municipios del país

- La AME potencia el uso de su modelo propio, pero éste no es conforme con estándares internacionales

- Muchos municipios tienen catastros expeditos sobre papel o simples ficheros Excel

- No es habitual utilizar sistemas georreferenciados

- La información generada por un área se queda en la propia área. No es posible compartir

- Cuando el catastro está en un SIG éste no es accesible a través de Internet

- En la mayoría de los casos, no hay acceso a la información catastral vía online

- No se dispone de la capa catastral para la toma de decisiones a niveles administrativos superiores.

\section{Propuesta: infraestructura nacional de datos catastrales}

Debido a ese aislamiento de la información catastral en Ecuador, la solución que aquí se defiende es la de diseñar e implementar una IDE de acceso ubicuo y dotada 
de usabilidad que garantice la eficacia, la eficiencia y la satisfacción de todos los usuarios a todos los niveles.

Lo que se propone es una Infraestructura Nacional de Datos Catastrales (en breve, una IDE Catastral). Un nodo central desde el que acceder a las IDE de los municipios que dispongan de su propia IDE estandarizada e interoperable y que proporcione -a los que no tengan los recursos suficientes - un sitio donde almacenar y gestionar su información, con acceso privado a la información de cada GAD por los responsables del catastro del propio GAD. La existencia de una IDE Catastral conforme a estándares solucionaría el problema de la integración de la capa catastral con otras capas territoriales y sus conceptos relacionados (política pública, inversión pública, catastro productivo, de riesgos, comercial, rural, urbano, registro de la propiedad, notarial, etc.) para la toma de decisiones. Se pone aquí énfasis en el hecho de que el interfaz de esa IDE debería disponer de un grado de usabilidad contrastado para que, con los permisos de acceso pertinentes, sean sencillas las labores fundamentales (a) cargar nuevos datos desde cualquier GAD; (b) modificar y actualizar los datos existentes; (c) compartir la capa catastral con otras instituciones y siendo la parcela una unidad que puede interactuar con muchas capas a todos los niveles, (d) proporcionar información acerca de las características de una, varias o la totalidad de las parcelas (Figura 1).

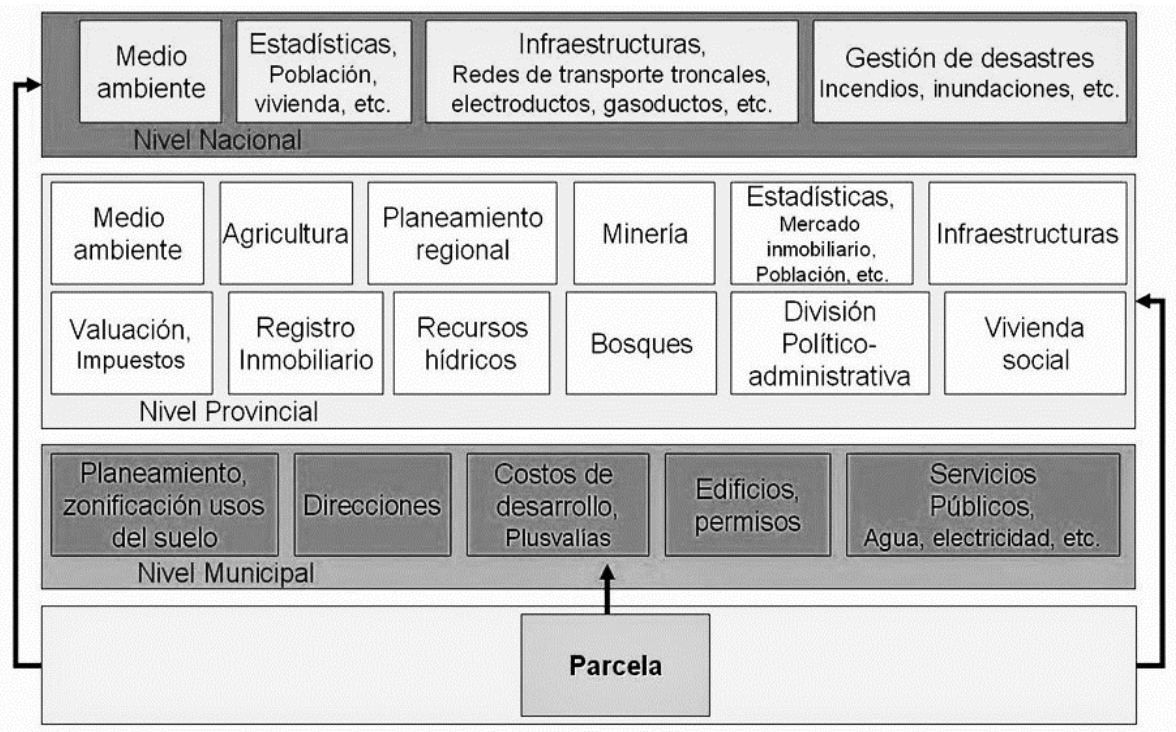

Figura 1. La parcela como referencia en la administración pública.

Fuente: De Ivars L.B. (2015). 
Esto no está en desacuerdo con la descentralización de los gobiernos autónomos ni contra la gestión municipal de sus recursos financieros generados por los impuestos catastrales. La actual situación, en la que hay multitud de tipos de archivos catastrales que no son interoperables, impide que los gobiernos (municipal y nacional) puedan tomar decisiones territoriales teniendo en cuenta otras capas que tienen que ver con el territorio, como el uso del suelo, el agua, el medioambiente y las circunstancias territoriales que pueden afectar a la población ecuatoriana como las amenazas y riesgos naturales, la seguridad alimentaria, la eficiencia energética, etc.

Por otra parte, la Comisión Permanente de Catastros de Iberoamérica (CPC, 2009) postula una Oficina Virtual de Catastro (OVC) (Serna et al., 2013) como es el caso de la OVC de Antioquia disponible en <http:// catastro.antioquia.gov.co/web/guest/inicio>, la exitosa Sede Electrónica del Catastro de España SEC < http://www.sedecatastro.gob.es/> o el reciente Sistema Integral de Modernización Registral y Catastral SIMCR mexicano <http:// www.ran.gob.mx/ran/index.php/simcr-info $>$. Creemos que las OVC se centran en disponer de una "ventanilla virtual" donde los usuarios puedan solicitar la información más habitual (Certificado Plano Predial Catastral; Certificado de Posesión de Bienes; Consulta estado de trámite; Descarga de Información Geográfica; Visualización del predio). Eso es útil al ciudadano, pero no a quienes necesitan la capa catastral para tomar decisiones junto a otras capas. Eso es lo que proporciona una IDE catastral como las existentes en Chile <http://www.catastro.cl/>, Tucumán (Argentina) <http://idet.tucuman.gob.ar $>0$ Uruguay <http://catastro.mef.gub. uy/12360/10/areas/geocatastro.html>, —éste último con visualizador de mapas, catálogo de metadatos, servidor de entidades WFS y de archivos "shape" - y otras, que ya han sido puesta en marcha en diferentes lugares (Data Catastro, 2011; Ivars, 2015). Sin embargo, como indican He et. al. (2012), no encontramos la usabilidad en los interfaces necesaria para que cualquier ciudadano o cualquier funcionario externo al servicio catastral pueda consultar con facilidad los datos generales (manteniendo la privacidad del propietario). No ocurre lo mismo en lo que se muestra en las Figuras 2 y 3 correspondientes al catastro suizo donde los usuarios disponen de una muy completa información general.

La aportación de nuestra propuesta a lo existente es que el geoportal de la IDE Catastral esté diseñado para todos los usuarios, cualquiera que sea su formación y sus intereses; que encuentren en el interfaz de comunicación una herramienta sencilla que cumpla los parámetros de usabilidad, interoperabilidad y responda a los estándares internacionales en materia de catastro.

Para disponer de un ejemplo de lo que se propone, se realizó un prototipo con los datos del GAD Mejía (Ecuador) <http://gestionterritorial.espe.edu.ec> cuyos primeros resultados pueden verse en la web. 


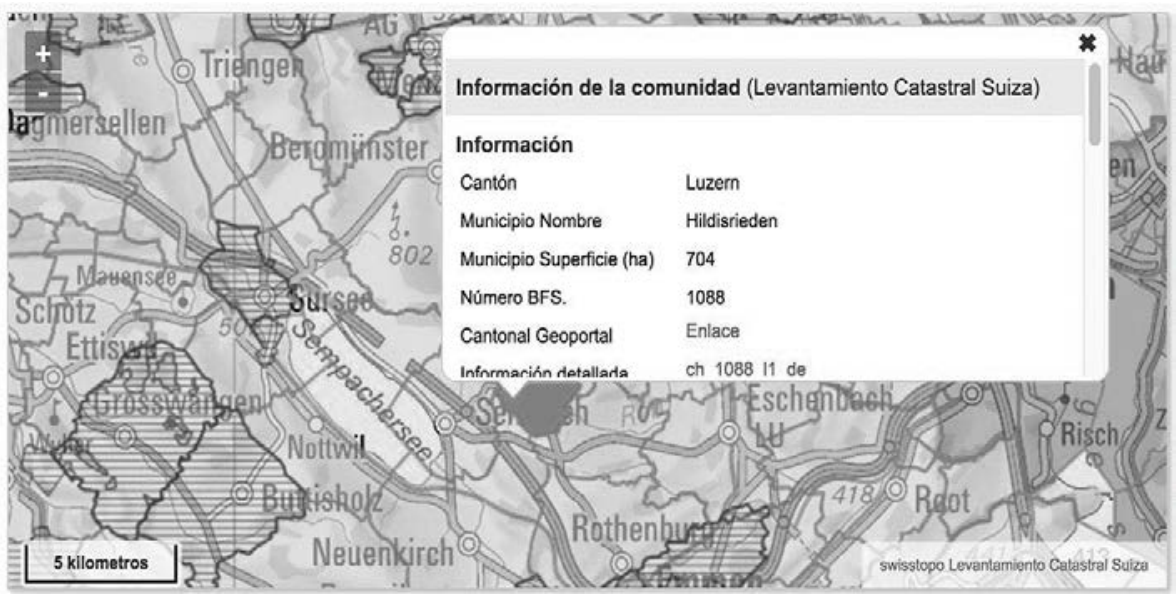

Figura 2. Al señalar con el ratón, el Catastro de Suiza muestra la información catastral asociada al cantón e incluso un enlace para llegar al servidor de catastro propio del cantón, en este caso de Lucerna. Véase la Figura 2.

Fuente: <https://rawi.lu.ch/themen/geoportal >.

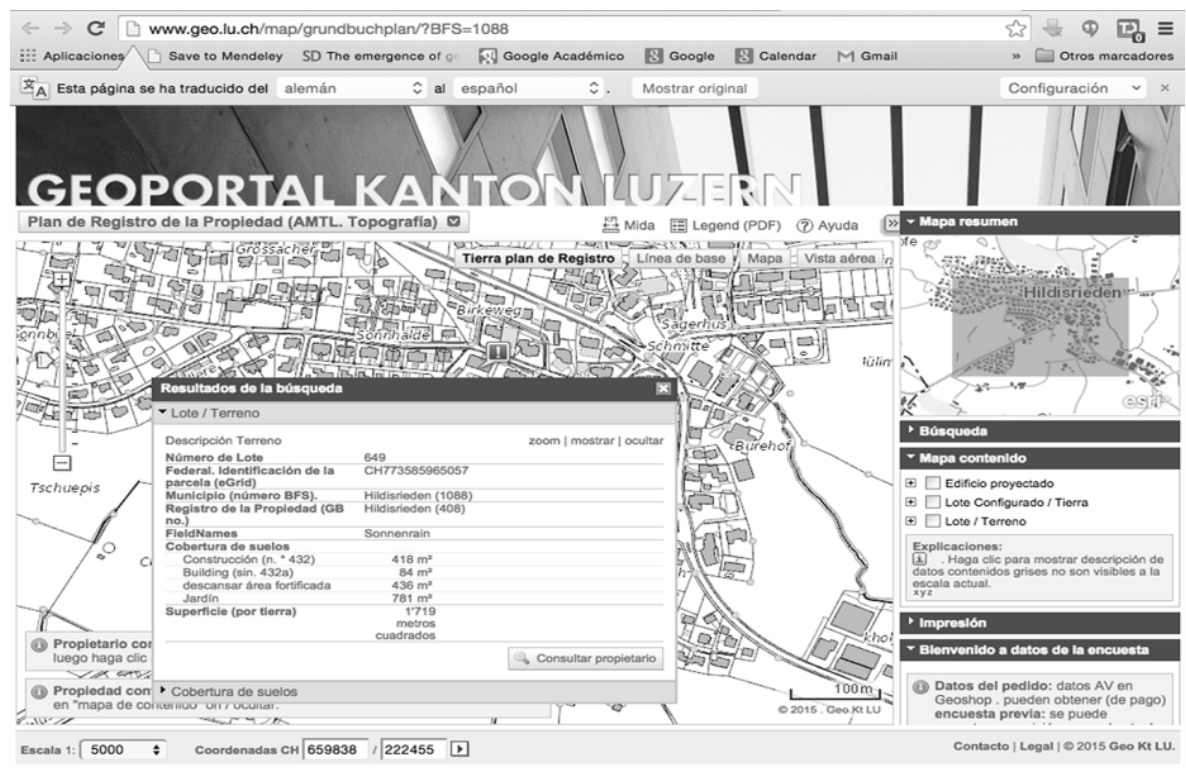

Figura 3. Información de cada predio en el Geoportal catastral de Lucerna.

Fuente: <https://rawi.lu.ch/themen/geoportal>. 
Las Figuras 4a-4f muestran distintas capas de una parte del GAD Mejía en la que en (a) aparecen los lugares poblados (puntos rojos); en (b) se ha añadido la capa de catastro urbano; la (c) muestra además, la capa del catastro de rústica; en (d) se ha incorporado la capa de uso potencial del suelo; en (e) se ha quitado la capa de usos y se ha añadido la de susceptibilidad de riesgos y en (f) se muestran las anteriores más la capa de peligro de inundaciones. Y todo ello viendo la capa catastral.

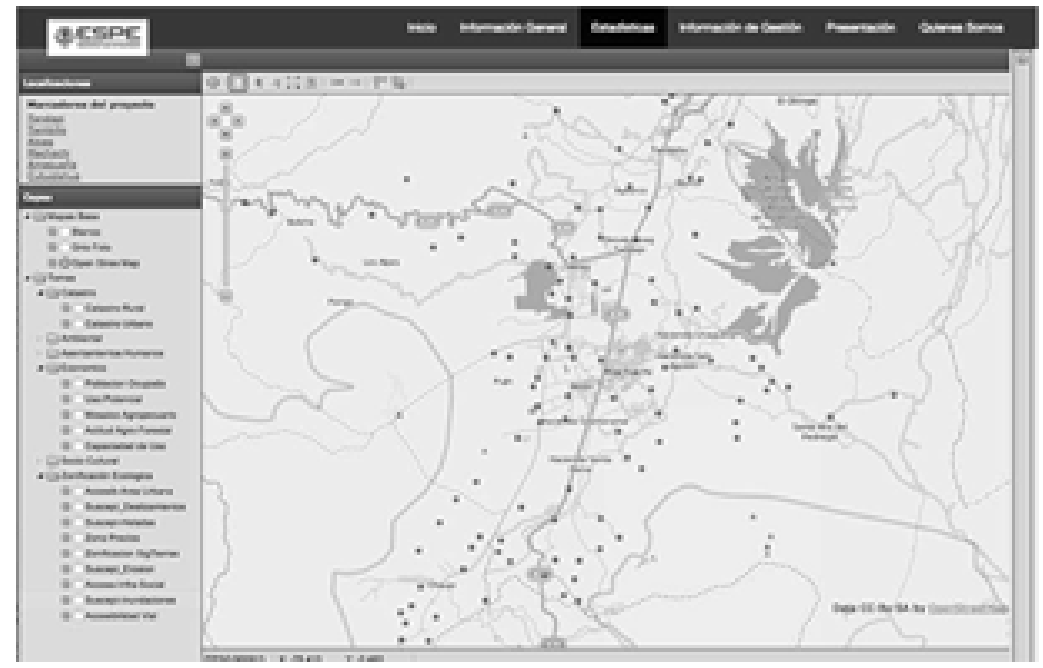

Figura 4a. Lugares poblados.

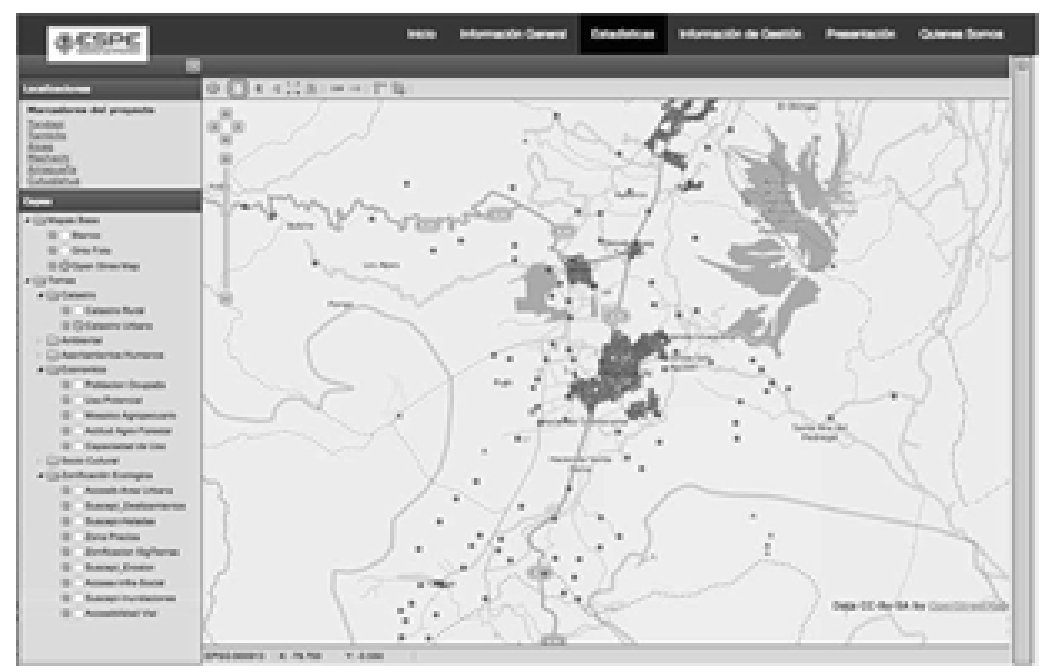

Figura 4b. Lugares poblados + capa catastral urbana. 


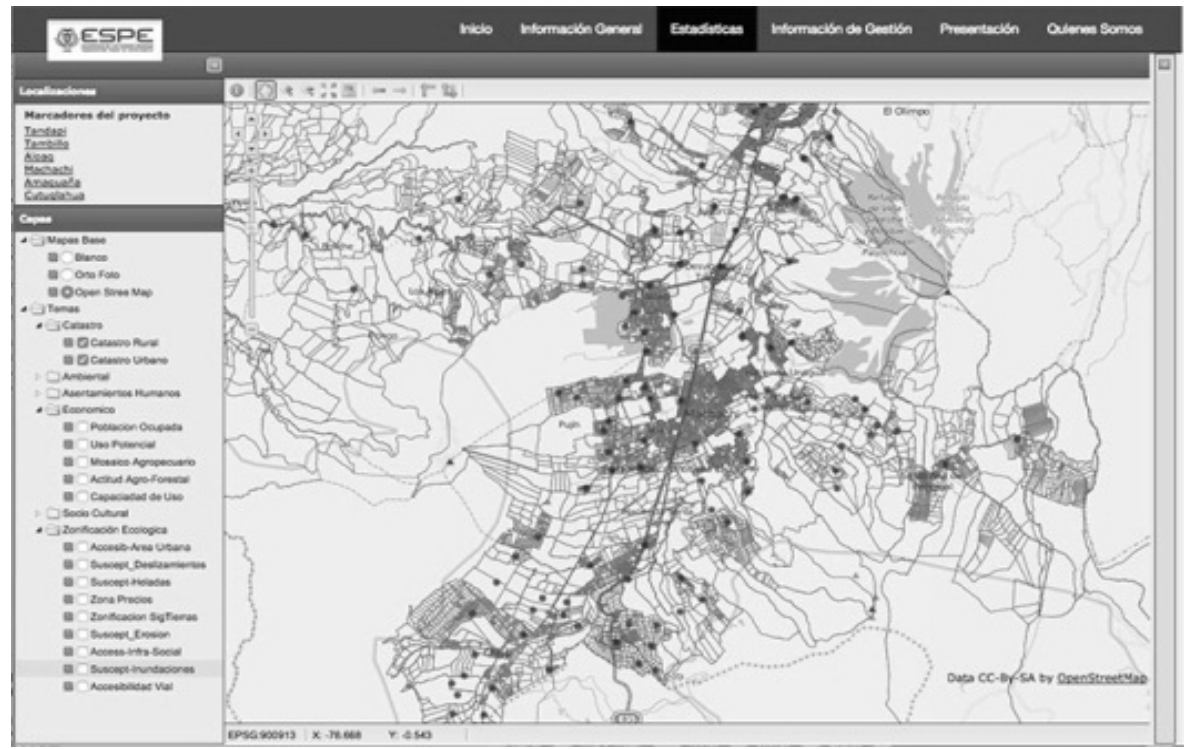

Figura 4c. Lugares poblados + catastro urbano + catastro de rústica.

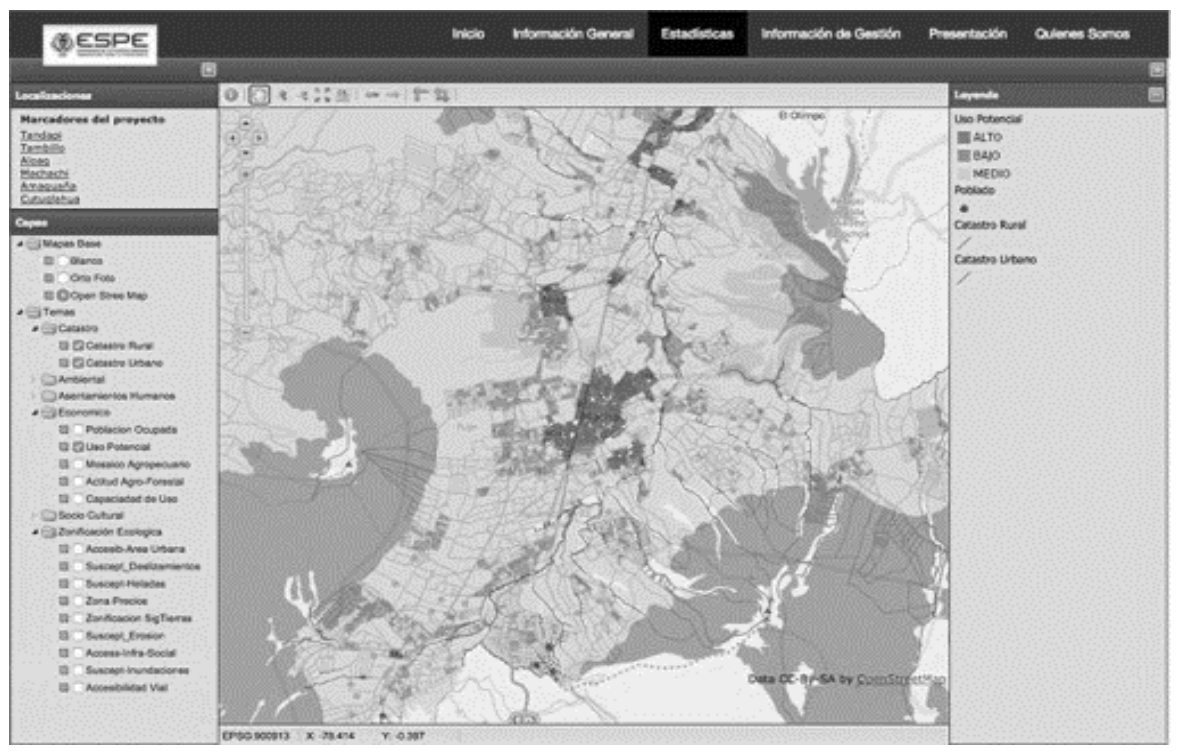

Figura 4d. Lugares poblados + capas catastrales + uso potencial del suelo. 


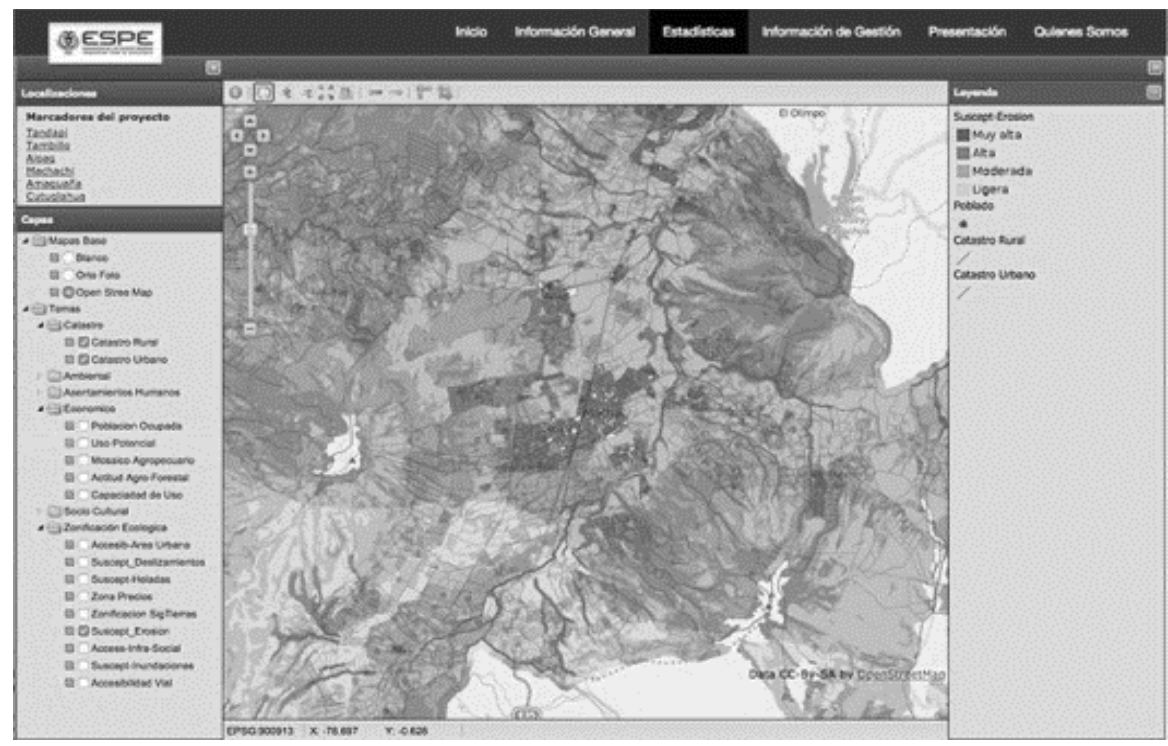

Figura 4e. Lugares poblados + capas catastrales + susceptibilidad de riesgos.

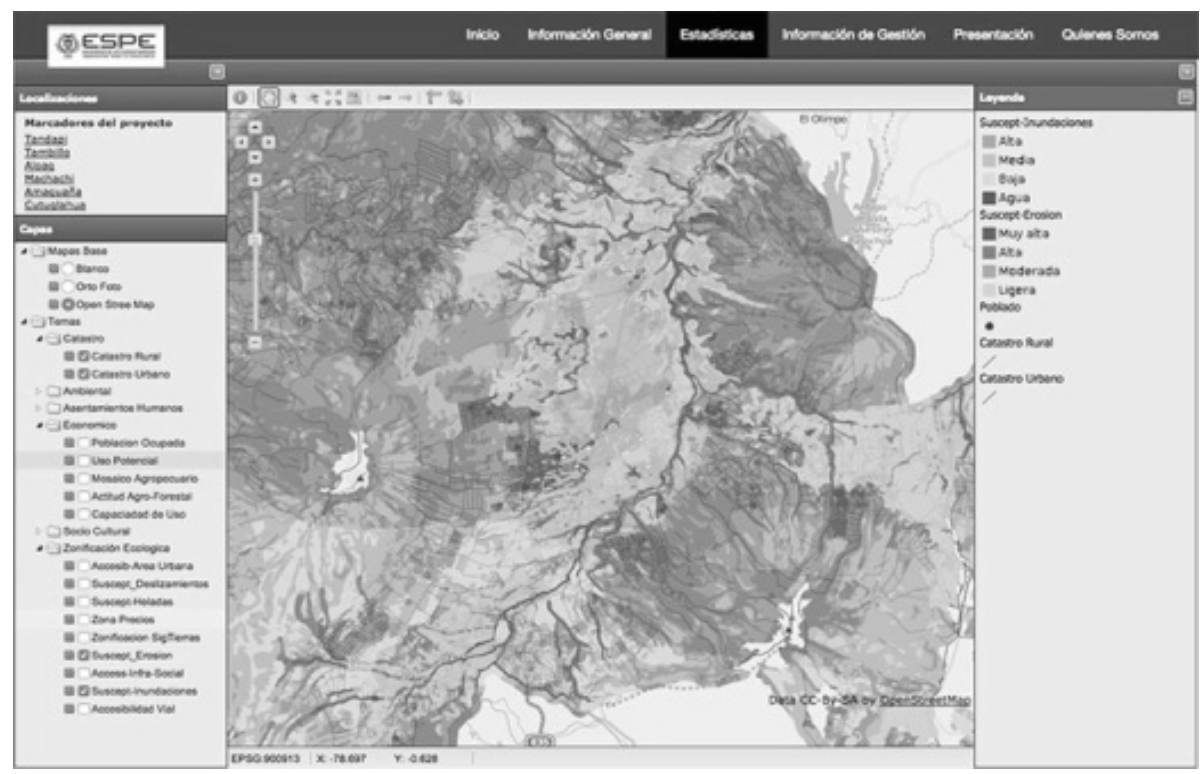

Figura 4f. Las capas de la figura $4 \mathrm{e}+$ peligros de inundaciones. Fuente: <http://gestionterritorial.espe.edu.ec>. 
El tamaño de estas imágenes no permite visualizar fácilmente las características mostradas, pero al menos proporciona información de la importancia que tiene la incorporación de la capa catastral a un sistema de gestión territorial integral (Kaiser, 2013) donde se encuentre la totalidad de la IG del GAD para visualizar y tomar decisiones sobre múltiples ocurrencias que pueden ocurrir sobre el territorio.

A continuación, se presentan una serie de características que se deberían considerar en la implementación de este geoportal catastral, donde la incorporación de nueva tecnología que facilite su uso adquiere gran relevancia.

\section{Modelo de dominio territorial}

Para garantizar la interoperabilidad necesaria de la Información Territorial con el resto de geoinformación de los GAD, se debe poner a disposición de los sistemas informáticos, un modelo de dominio específico para la administración de territorios que:

- Sea conforme con la norma ISO 19152 (ISO LADM, 2012),

- Cumpla con estándares OGC [20] e ISO 19100 [21] en una implementación IDE

Esto con el objeto de conseguir una plataforma de acceso ubicuo y fácilmente accesible que permita incorporar los datos territoriales de los GAD, gestionarlos, actualizarlos y usarlos para la toma de decisiones en política, inversión pública e información ciudadana. El esquema conceptual de este modelo de administración de territorios, desarrolla dos aspectos fundamentales (Cámara et al., 2010):

- Los derechos, responsabilidades, restricciones y la necesidad de que exista una documentación legal que relacione cada objeto territorial (parcela, vivienda, construcción, etc.) con los sujetos titulares del derecho sobre ellos (personas físicas, jurídicas, etc.).

- Los aspectos geométricos y espaciales de los objetos anteriores, donde no solo se admiten definiciones geométricas posicionales, sino que admite también textos descriptivos. Cada país tiene la potestad de personalizar su propio perfil de LADM (Cámara et al., 2010), [22] eliminando unos elementos, modificando otros o incluso añadiendo nuevos para que se ajuste a las necesidades de las administraciones de cada país.

\section{Servidor estatal en la nube}

Lo anterior podría realizarse situando un nodo web en las dependencias de cada GAD pero los diferentes requisitos tanto tecnológicos (24/7, velocidad de acceso) 
como financieros de los GAD, conduciría a duplicar esfuerzos y gastos de mantenimiento. Apoyamos la idea de que la información de todos los GAD que no dispongan de un equipo humano y tecnológico sostenible, se sitúe en una nube estatal de Internet, donde los diferentes niveles de gobierno (central, provincial, cantonal y parroquial) y los ciudadanos, puedan consultar su información con las restricciones particulares de acceso a los datos privados y de gestión que las normas establezcan.

\section{Interoperabilidad jurídica Catastro-Registro-Notarías}

Para que la información de todos los GAD que se cargue en ese sistema sea homogénea, se deberían desarrollar formularios de carga comunes, que dentro de la complejidad de este tipo de información, sean de fácil manejo, donde los responsables de la catalogación o modificación de la información de cada municipio (ya sean especialistas en IG o simples usuarios de ofimática ajenos al tratamiento de cartografía digital, a bases de datos y a análisis espacial) pudieran cargar las bases de datos catastrales a través de Internet, teniendo así certeza de que cada predio estará definido por un conjunto común de metadatos mínimos en todo el país (Navarro, 2013). El modelo, además de ser un descriptor del ámbito espacial del derecho a esas propiedades, debe estar preparado para servir al Registro de la Propiedad como descriptor legal con valor jurídico de los inmuebles urbanos y rurales, pues ninguna dimensión (ya sea dimensión conceptual, temporal, espacial, formal, finalitaria o jurídica) del Registro ni del Catastro son exclusivas de uno o de otro organismo, sino que son compartidas (Vázquez, 2013). Esto es un claro ejemplo de interoperabilidad jurídica (Díaz, 2012). Aparece aquí la pregunta ¿por qué un mismo objeto territorial es descrito de forma diferente en el Catastro y en el Registro de la Propiedad siendo una única entidad? En algunos países ya se ha legislado para que exista esa coordinación y lo mismo puede aplicarse a la acción notarial (Calero, 2010). Aplicaciones de escritorio con un claro intento de interoperabilidad entre catastro y notarías ya han sido desarrolladas para la gestión en notarías de expedientes de alteraciones catastrales (Llorens, 2005; Jiménez, 2014), posibilitando "una vía extrajudicial, eficiente y barata para resolver con precisión y agilidad el complicado problema de la concordancia catastral y registral” (Díaz, 2013). Lo que aquí se sugiere es que esa aplicación no sea una herramienta de escritorio, sino que esté accesible desde la web y que desde Internet queden registradas todas las alteraciones.

\section{Geoportal usable}

Las IDE, se hacen visibles a través de los denominados geoportales, que son aplicaciones web que actúan como un punto de entrada a la IG distribuida y disponible 
para ser compartida (European Commission, 2005). Se dice que el geoportal es a una IDE lo que el escaparate es a un comercio (Manrique, 2012) siendo necesario que el usuario no se sienta rechazado por las dificultades que encierre su uso. A pesar de las recomendaciones internacionales relacionadas con la IG (GEOSS, 2008) y Latinoamericanas específicamente (IPGH, UN-GGIM: Américas, GEOSUR, IDE Andina) acerca de la facilidad de uso que deben mostrar los geoportales, no parece que se haya puesto mucho énfasis en ello. No hay más que compararlos con otros entornos web comerciales (banca, compras on-line, entretenimiento) en los que el interfaz amable es una garantía de fidelización de los usuarios (Bernabé, 2014).

El diseño que presentan en general los geoportales IDE, no responde a las necesidades de los distintos perfiles de usuarios que pueden acceder en busca de IG, desde profesionales hasta usuarios ocasionales de IG pasando por los de perfil medio. Esta falta de preparación del geoportal a los usuarios determina un uso limitado y en algunos casos que solo sean utilizados por profesionales de la IG muy especializados. El problema reside, en general, en la falta de usabilidad que presentan los geoportales, entendiendo por usabilidad como “...la efectividad, eficiencia y satisfacción con la que un producto permite alcanzar objetivos específicos a usuarios específicos en un contexto de uso específico” (ISO/IEC 9241, 1998):

- La eficacia o precisión y grado de consecución con que los usuarios logran objetivos establecidos (ISO 9241-11: 1998. 3.2).

- La eficiencia o relación entre los recursos empleados y la precisión y el grado de consecución con que los usuarios logran objetivos establecidos (ISO 9241-11: 1998. 3.3).

- La satisfacción o ausencia de incomodidad y existencia de actitudes positivas hacia la utilización del producto (ISO 9241-11: 1998. 3.4).

Para medirlas se utilizan distintas metodologías, como por ejemplo: diseño centrado en el usuario (DCU), diseño orientado a metas, entrevistas contextuales, evaluación heurística, etc. En el marco de los geoportales, la metodología aplicada en el proyecto GeoTest (He et. al., 2012), resulta una de las más conocidas (y con resultados sorprendentes que demuestran la baja usabilidad de los geoportales IDE y de las herramientas que incorporan). Las metodologías SUM- Single Usability Metric (Sauro, 2015) y SUS- System Usability Scale (Brooke, 1996), pueden adaptarse para medir la usabilidad de los geoportales IDE. En el entorno latino también se han realizado medidas de la usabilidad de geoportales (Moya, 2007) siendo en la actualidad un tema de claro interés (Jiménez, 2014). 


\section{Usabilidad general del sistema}

Puesto que la capa catastral dispone de información relevante para otras entidades estatales, la posibilidad de tomar decisiones conjuntas con esta capa y con otras provenientes del mismo GAD o de otras instituciones, por ejemplo, la capa de "cultivos y aprovechamientos” de la institución provincial o estatal correspondiente, debería ser una acción trivial. Sin embargo, lo normal es que no lo sea, pues el diseño de la interacción de estas páginas web no está avalado por la participación de especialistas de comunicación (He, 2012; Resch, 2013). El diseño y la interacción en los geoportales evidencian que se pone más interés en la tecnología que en los usuarios (Aditya, 2005). Los usuarios sin una formación especializada no saben cómo realizar preguntas al sistema. Este problema de falta de usabilidad conduce a que sea necesaria la existencia de un servicio informático que se convierte en "interlocutor" entre las preguntas que quiere hacer el que tiene que tomar decisiones y el sistema informático que soporta las bases de datos. Particularizando para el caso del catastro, debido a esta falta de usabilidad de los geoportales, los responsables de las tomas de decisión de los GAD, a no ser que sean expertos en las consultas tipo SQL, no tienen facilidad para realizar consultas por sí mismos a las bases de datos relacionadas con a) la inversión pública ("Dónde es más rentable la inversión pública?”, “¿qué parcelas tienen el mejor índice para el cultivo del trigo?”, “¿qué predios serán expropiados por la ampliación de la vía?”, “¿qué trazado debe tener la línea eléctrica para que las expropiaciones sean mínimas?”, etc.); b) con los impuestos prediales (“¿Qué predio no ha pagado en impuesto catastral este año?”, “¿qué predios o construcciones están a nombre de Fulanito de Tal?”, etc.); c) con los intereses de los usuarios (“¿Cuándo y cuánto debo pagar por el impuesto catastral?”).

Estas dificultades de comunicación con el sistema informático donde sólo los expertos son capaces de obtener respuestas, son causadas por la carencia de interfaces amigables y dotadas de usabilidad que interactúen de una forma transparente con las bases de datos catastrales.

\section{Incorporación del lenguaje natural y la semántica}

Al contrario de los lenguajes formales (matemáticos, lógicos, informáticos, entre otros), el lenguaje natural de los humanos utiliza conceptos “difusos” que no tienen referentes precisos y que no están delimitados por fronteras semánticas concretas (Montello, 2005) sino que en muchos casos (cuando los conceptos están elípticos o son anáforas) toman su significado en base al contexto de la conversación (Androutsopoulos, 1995). A pesar de eso, desde principios de la década de los noventa, (Wang, 1994) se viene trabajando en el desarrollo de sistemas automáticos que permitan a los SIG comunicarse con los usuarios en sus lenguajes naturales. 
La idea de utilizar el tratamiento del lenguaje natural y recursos o técnicas de recuperación de IG en base a diccionarios, tesauros y ontologías, para facilitar una interface de acceso más amigable, ya fue expuesta cuando se trabajaba en los inicios de la IDE de España (Bañares, 2001). Se basa en que el usuario que necesite unos datos, debe solicitarlos como si tuviera enfrente al dependiente de una tienda especializada. Éste debe entender lo que el cliente quiere y debe también saber de qué documentos dispone en su comercio, evaluando la relevancia de cada documento disponible para satisfacer la pregunta realizada. De igual manera, el usuario, frente a una IDE, debe formular su pregunta y el sistema debe localizar la mejor respuesta entrando en los servicios de catálogo o en la base de datos de metadatos, identificando los conceptos o temas de interés de la pregunta y gestionando la recuperación de la información. El éxito de esta respuesta está en relación directa con la cantidad de datos almacenados y la disponibilidad para que éstos sean accesibles. Las ventajas son a) que el usuario no debe ser un experto en lenguajes de consulta tipo SQL (Androutsopoulos, 1995); b) que el usuario puede usar su lenguaje natural; c) que el lenguaje natural permite expresar preguntas que no serían fáciles de realizar por medio de formularios. Entre las desventajas están a) la falta de restricciones lingüísticas que soportaría el sistema; b) la cantidad de expresiones que debe reconocer el sistema; c) la falta de conocimiento acerca de una respuesta vacía (¿Es que no hay datos?, ¿no se ha entendido la pregunta?) (Bañares, 2001).

Lo que aquí se sugiere, como en otros campos cercanos relacionados con la geolocalización (Abchir, 2013), es que los requerimientos de los usuarios puedan ser formulados utilizando el lenguaje natural, mediante un asistente virtual -basado en voz o en texto- que incorpore el procesado de lenguaje natural y enriquecimiento semántico y que el sistema responda (con diferente grado de privacidad) a las preguntas más elementales realizadas por el Gobierno Central, los GAD y los ciudadanos. El usuario debería poder escribir (o decir verbalmente) “Añadir (agregar, incorporar, adicionar, anexionar, sumar) la capa de riesgos de incendios" y el sistema que debe saber lo que es “Añadir una capa”; encontrar qué organismo está encargado de evaluar los riesgos de incendio (de la zona o de la provincia o de la totalidad del estado) y localizar la capa "riesgos de incendios". Finalmente debería presentar el resultado. En las figuras siguientes se muestra un ejemplo ficticio para aclarar el concepto. Las cinco primeras figuras corresponden a capas de un mismo servidor, el de la IDE de Euzkadi <http://www.geo.euskadi.eus/>. La capa añadida en la Figura 10 se ha importado de otro servidor externo, específicamente del servicio de mapas del Instituto Geológico y Minero < http://mapas.igme.es/>. 


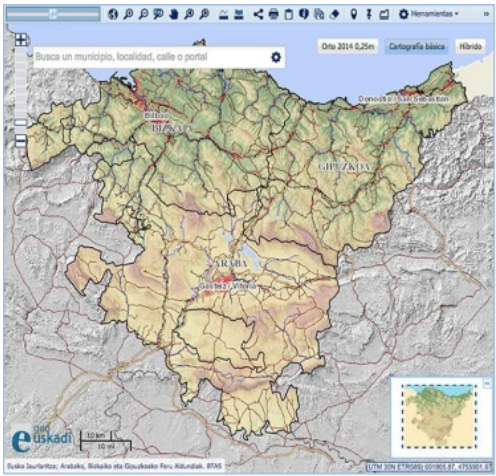

Figura 5. El usuario ha solicitado "Ver el Visualizador de Euzkadi”.

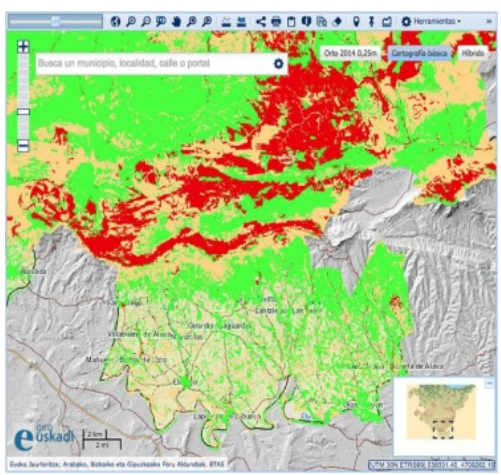

Figura 7. El usuario ha solicitado "Añadir capa de riesgo de incendio".

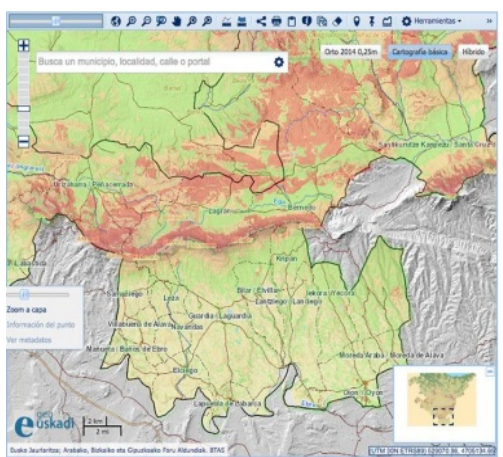

Figura 9. El usuario ha solicitado "Más transparencia a la capa de riesgo de incendio".

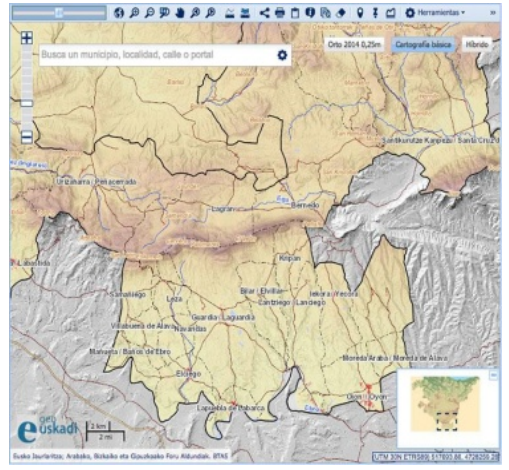

Figura 6. El usuario ha solicitado "Acercar y centrar vista en Lagrán”.

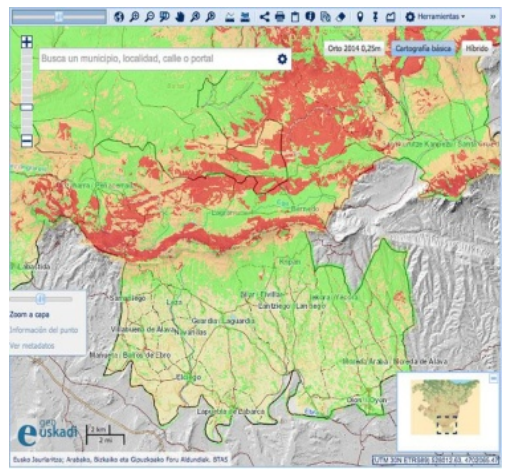

Figura 8. El usuario ha solicitado " $50 \%$ de transparencia a la capa de riesgo de incendio".

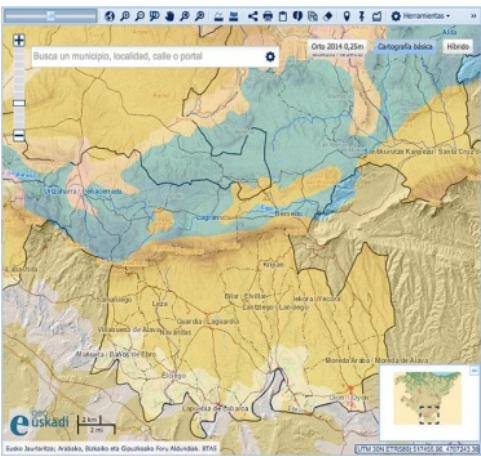

Figura 10. El usuario ha solicitado "Importar capa de litología y aplicar transparencia del 50\%”. 
Puesto que lo que aquí se propone está dirigido a todo tipo de usuarios, se supone que el asistente virtual que se diseñe deberá disponer de un grado de usabilidad que garantice su uso sin necesidad de complicados manuales. Esta facilidad de uso la tienen los asistentes vía voz como Siri de Apple, Cortana de Microsoft, Google Now, Vlingo, o S-Voice de Samsung, o el opensource Mycroft que son ejemplos que pueden ser implementados para realizar búsquedas en SIG (Seedah, 2014) y que demuestran que una infraestructura de procesamiento del lenguaje basada en la nube puede soportar interacciones en servicios móviles (Johnston, 2014). Otros asistentes virtuales basados en texto, ya sean para equipos móviles o fijos como los aplicados por Renfe < http://www.renfe.com/> y por la Universidad de Granada (España) <http://tueris.ugr.es/elvira/> en sus páginas corporativas, responden con bastante grado de acierto a preguntas cuya respuesta puede generarse mediante la información de sus bases de datos.

En el ejemplo que se presenta en la Figura 11 del asistente virtual de la Red Nacional de Ferrocarriles Españoles (Renfe), se ha realizado una consulta verbal a través del micrófono del ordenador de sobremesa: “Quiero ir el martes que viene a Barcelona”. El sistema, como se ve en la figura, ha detectado:

a. La fecha en la que se realiza la pregunta (24 de marzo de 2017)

b. Lo que significa "El martes que viene” (28 de marzo de 2017)

c. El sitio desde donde se genera la pregunta (Madrid).

El sistema ha generado, en menos de 20 segundos una respuesta, con lo que supone es la información solicitada.
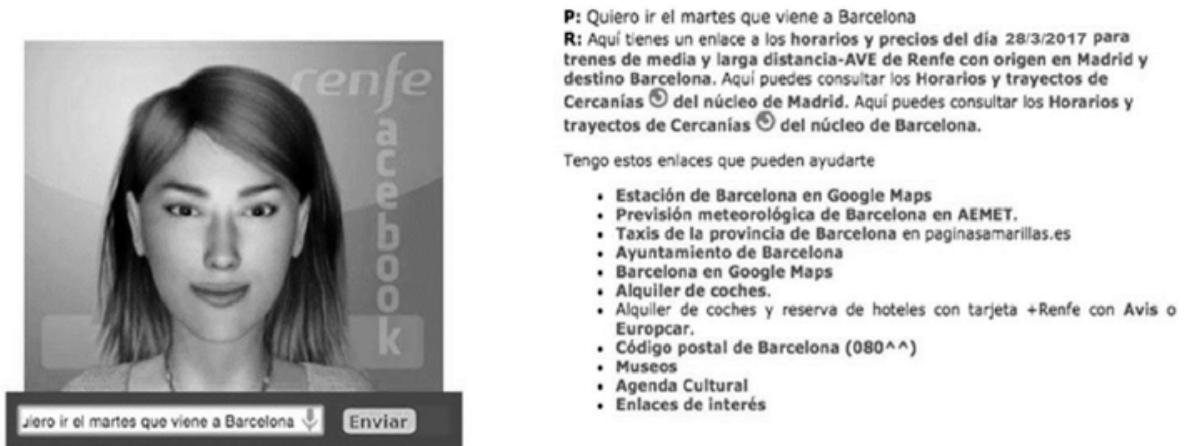

Figura 11. Asistente Virtual de Renfe.

Fuente: <http://goo.gl/pLi5L3>. 


\section{Conclusiones}

La autonomía para que los Gobiernos Autónomos Descentralizados (GAD) de Ecuador puedan generar su propio Catastro sin ajustarse digitalmente a estándares, conduce a perder la posibilidad de que la capa catastral pueda interoperar con las capas de las Infraestructuras de Datos Espaciales (IDE) del país.

Se considera trascendental que alguna organización nacional como la Asociación de Municipios de Ecuador (AME) u otras con (y por) mandato gubernamental, lideren la estandarización del catastro del país.

El país debería adoptar la norma ISO 19152 (LADM - Land Administration Domain Model) para garantizar que la información catastral será interoperable.

Las Oficinas Virtuales del Catastro (OVC) facilitan a los usuarios la tramitación de su documentación catastral, pero no solucionan el problema de la falta de interoperabilidad de la capa catastral con otras capas territoriales.

Se considera necesario que en países como Ecuador exista una Infraestructura Nacional de Datos Catastrales, desde cuyo geoportal se acceda a los nodos de todo el catastro del país.

Debido a la falta de usabilidad de los geoportales de las IDE, se plantea la necesidad de investigar en esta materia y proporcionar a las interfaces de los geoportales de catastro la usabilidad que disponen otros servicios de la sociedad como los de ventas a través de la web, entretenimiento, banca, etc.

Los geoportales catastrales tienen que poner el énfasis en los usuarios más que en las tecnologías, que deberían ser transparentes a ellos.

Debido a la importancia de la capa catastral para la toma de decisiones en cuestiones relacionadas con el territorio a todos los niveles, se considera que la implementación de asistentes virtuales, que proporcionen respuestas basadas en los metadatos del catastro, podría facilitar el uso de los geoportales a los usuarios no expertos.

\section{Bibliografía}

Abchir, M.A., Truck, I. and Pappa, A. (2013). "Dealing with natural language interfaces in a geolocation context", in The 10th International FLINS Conference on Computational Intelligence in Decision and Control, pp. 806-811.

Aditya, T. and Kraak, M.J. (2005). "Reengineering the Geoportal: Applying HCI and Geovisualization Disciplines”, in 11 th EC GI \& GIS Workshop ESDI: Setting the Framework Sardinia, June, 92 pp.

Andreoutsopoulos, I.; Ritchie, G.D. and Thanisch, P. (1995). "Natural Language Interfaces to Databases. An Introduction”, Journal of Natural Language Engineering, Cambridge University Press. 
Bangora, A.; Kortumb, P. and Millerc, J. (2008). "An Empirical Evaluation of the System Usability Scale”, Intl. Journal Of Human-Computer Interaction, vol. 24, núm. 6, Taylor \& Francis Group, pp. 574-594.

Bañares, J.A.; Bernabé, M.A.; Gould, M.; Muro-Medrano, P.R. y Zarazaga, F.J. (2001). "Aspectos tecnológicos de la creación de una Infraestructura Nacional Española de Información Geográfica”, Mapping, núm. 67, pp. 68-71.

Bernabé-Poveda, M.A. y González, M.E. (2014). "Sobre la necesaria usabilidad de los geoportales como puertas de entrada a las IDE”, Geofocus Revista Internacional de Ciencia y Tecnología de la Información Geográfica, núm. 14, pp. 1-5.

“BEST-GIS” ESPRIT/ESSI Project n. 21580. Section 3 "Overview of user-centred design of GIS user interfaces” Recuperado de <http://www.geo.info.hu/ uniphorm/best/Guides/chapter3/three.htm\#top>.

Brooke, J. (1996). "SUS-A quick and dirty usability scale". Usability evaluation in industry, vol. 189, no 194, pp. 4-7. Recuperado de <http://hci.liacs.nl/ files/SUS-questionaire.pdf $>$.

Calero, C.M. (2010). "Coordinación del Catastro con el registro de la propiedad y con las escrituras públicas, y de todos ellos con la realidad”, Revista jurídica del notariado, núm. 73, pp. 409-546.

Cámara, M.A.U.; Balboa, J.L.G. y López, F.J.A. (2010). “Análisis de la propuesta ISO 19152 (Land Administration Domain Model)”, in Catastro: formación, investigación y empresa: Selección de ponencias del I Congreso Internacional sobre catastro unificado y multipropósito, pp. 103-116.

Constitución de la República del Ecuador (2008). Decreto Legislativo, Registro Oficial 449 del 20 de octubre de 2008, Montecristi, Ecuador.

COOTAD, Código Orgánico de Organización Territorial, Autonomía y Descentralización (2010). Ley 0, Registro Oficial Suplemento 303 de 19 de octubre de 2010, Quito, Ecuador.

CPC. III Reunión del Comité Permanente sobre el Catastro en Iberoamérica (2009). Recuperado de <http://www.catastrolatino.org/documentos/declaracion_ cartagena_2009.pdf $>$.

Data Catastro (2011). No 3, 20. Recuperado de $<$ http://www.catastrolatino.org/documentos/Datacatastro_edicion_3.pdf >

Díaz Díaz, E. (2013). “Alteración catastral telemática e inscripción registral”, Revista El Notario del siglo XXI. Revista del Ilustre Colegio Notarial de Madrid $\mathrm{N}^{\circ}$ 51. Recuperado de <http://www.elnotario.es/index.php/practicajuridica/ 3551-alteracioncatastral-telematica-e-inscripcion-registral>.

- E. (2012). Interoperabilidad jurídica de la Geoinformación. III Jornadas Ibéricas de Infraestructuras de Datos Espaciales. Madrid. Recuperado de 
$<$ http://www.idee.es/resources/presentaciones/JIIDE12/miercoles/C18. Articulo.pdf $>$.

Erba, D. A. (2008). "El Catastro Territorial en América Latina y el Caribe”. Lincoln Institute of Land Policy. Recuperado de <https://www.lincolninst.edu/ pubs/dl/1373_694_livro_america_latina_mar2008.pdf>

European Commission (2005). "Standardisation Mandate to CEN, CENELEC and ETSI in support of European Accessibility Requirements for public Procurements of Products and Services in the ICT Domain”. Recuperado de $<$ http://www.ictsb.org/Working_Groups/DATSCG/Documents/M376.pdf>.

Garrido, T.; Francisco, J.; Cajero Bravo, J.; Bribiesca Martínez, L.; Castro González, N. y Martínez Velázquez, F. (2011). "gvSIG, una aplicación unificada al catastro municipal mexicano. La modernización del catastro y del Cobro del Impuesto Predial en municipios con 25,000 predios o menos”, VII Jornadas internacionales gvSIG.

He, X.; Persson, H. and Östman, A. (2012). “Geoportal usability evaluation”, International Journal of Spatial Data Infrastructures Research, no. 7, pp. 88-106. Recuperado de <http://ijsdir.jrc.ec.europa.eu/index.php/ijsdir/article/view File/248/323>.

INEC (2010). División Político Administrativa. Recuperado <http://goo.gl/ aqUUVm>.

INSPIRE (2007). Directiva 2007/2/CE del Parlamento Europeo y del Consejo de 14 de marzo de 2007. Diario Oficial de la Unión Europea (L108/1). Recuperado de <http://eurlex.europa.eu/LexUriServ/LexUriServ.do?uri=OJ:L:2007:108: 0001:0014:es:PDF>.

ISO LADM (2009). Geographic information - Land Administration Domain Model (LADM).

ISO 19152.Land Administration Domain Model. Recuperado de $<$ http://www.iso.org/iso/catalogue_detail.htm\%3Fcsnumber\%3D51206>.

ISO/CD 19152. International Organization for Standarization. Lysaker, Noruega.

ISO 9241-11:1998 Ergonomic requerimients for office work visual display terminal (VDTs) Part 11: Guidance on usability. Recuperado de <http://www.iso.org/ iso/catalogue_detail.htm?csnumber=16883>.

ISO 19100. En ISO/TC211 Geographic information/Geomatics: $<$ http://www.isotc211.org/>

Ivars, L.B. (2015). "El Catastro en las IDE, Catastro y Territorio”. Recuperado de $<$ http://catastroyterritorio.blogspot.com.es/2015/03/el-catastro-en-lasinfraestructuras-de.html>.

Jiménez Calderón, L.; Yépez Campoverde, J. y Vázquez Hoehne, A. (2014). "El usuario como factor de éxito en el diseño de un geoportal”, GeoFocus (Artículos), núm. 14, pp. 181-210. 
Jiménez Clar, A. y Fernández Moreno, M. (2014). “Acerca de la revisión de los sistemas de gestión jurídica de la información territorial”, Tecnologías de la información para nuevas formas de ver el territorio: XVI Congreso Nacional de Tecnologías de Información Geográfica, AGE.

Johnston, M.; Chen, J.; Ehlen, P.; Jung, H.; Lieske, J.; Reddy, A.; Selfridge, E.; Stoyanchev, S.; Vasilieff, J. and Wilpon, J. (2014). "MVA: The Multimodal Virtual Assistant”, in 15th Annual Meeting of the Special Interest Group on Discourse and Dialogue, Philadelphia, USA, pp. 257-259.

Kaiser, C.; Vásquez, A. y Vásquez, D. (2013). "Manual de gestión inclusiva de emergencias: derechos humanos de las personas con discapacidad durante emergencias”. Recuperado de <http://publicaciones.ops.org.ar/publica ciones/publicaciones\%20virtuales/ GestionInclusiva/ManualGI.pdf>.

Llorens Cobos, F.; Mira Martínez, J.M.; Navarro Carrión, J.T. y Ramón Morte, A. (2005). "Proyecto Ramón Llull: Sistema de gestión de alteraciones catastrales para las notarías de la Comunidad Valenciana”, I Jornadas De SIG Libre, $1-12$.

Manrique, M.T. y Manso, M.A. (2012). "Los geoportales. Perspectiva desde la usabilidad, en Bernabé-Poveda”, M.A. y López-Vázquez, C.M. Fundamentos de las Infraestructuras de Datos Espaciales, Madrid, UPM Press, Serie científica.

Montello, D.R. and Freudschuh, S. (2005). “Cognition of Geographic Information”, en McMaster, R.B. and Usery, E.L. (eds). A research agenda for geographic information science, Boca Ratón, FL, CRC Press, pp. 61-91.

Moya Honduvilla, J. (2007). Análisis y diseño de alternativa al geoportal de la Infraestructura de Datos Espaciales de España (IDEE). Aplicación de la Metodología de Diseño Orientado a Metas (DOM) de Alan Cooper. Proyecto Fin de Carrera / Trabajo Fin de Grado. EUITT. UPM. España. Recuperado de <http://oa.upm.es/4970/1/PFC_JAVIER_MOYA_HONDUVIL LAB.pdf>.

Navarro Carrión, J.T. y Ramón Morte, A. (2013). “Importancia de los procesos de validación topológica en la gestión de alteraciones catastrales”, Investigaciones Geográficas, Nº 60.07, pp. 17-138.

OGC, Open Geospatial Consortium. Listado de estándares. Recuperado de $<$ http://www.opengeospatial.org/standards/is>.

Pogue, D. (2012). "Why siri is still the future". Recuperado de <https:// www.scientificamerican.com/article/why-siri-is-still-future/>.

Requisitos para el geoportal de GEOSS (2009): GCI Consolidated Requirements. Recuperado de <http://www.earthobservations.org/documents/gci/gci_ requirements_20090312.doc>. 
Resch, B., Zimmer, B. (2013): "User experience design in professional map-based Geo-Portals”. ISPRS International Journal of Geo-Information, no. 2, pp. 1015-1037.

Reyes Bueno, F., Miranda Barrós, D. y Crecente Maseda, R. (2012). "Situación de la valoración catastral rural”, CT/Catastro. Recuperado de <http:// www.catastro.meh.es/documentos/publicaciones/ct/ct75/3.pdf>.

Rodríguez Egüez, V. (2012a). "Experiencias comparadas del impuesto predial en Ecuador. Instituto Lincoln de Políticas del Suelo”. Recuperado de $<$ https://goo.gl/3hZZeQ>.

—. (2012b). "Análisis del impuesto predial”. Recuperado de $<$ https://prezi.com/atnsemavx6wk/analisis-del-impuesto-predial/>.

Rodríguez, A.; Abad, P.; Sánchez, A.; González, C.; Soteres, C.; Juanatey, M.; Potti, H. y Fernández. X. (2009). Propuesta para aumentar la interoperabilidad de geoportales y visualizadores". Recuperado de <http://www.idee.es/ resources/presentaciones/GTIDEE_Murcia_2009/ARTICULOS_JIDEE2009 /Articulo-65.pdf>.

Sauro, J., and Kindlund, E. (2005). "A method to standardize usability metrics into a single score", in Proceedings of the SIGCHI conference on Human factors in computing systems, ACM, pp. 401-409.

Sauro, J. (2005). "SUM: Single Usability Metric". Recuperado de $<$ https://measuringu.com/sum-2/>.

. (2011). "Measuring usability with the system usability scale (SUS)". Recuperado de $<$ https://measuringu.com/sus/>.

Seedah, D.P.K. (2014). "Retrieving information from heterogeneous freight data sources to answer natural language queries", Doctoral Thesis. Recuperado de $<$ http://repositories.lib.utexas.edu/handle/2152/28341>.

SENPLADES, Secretaría Nacional de Planificación y Desarrollo. (2013). "Plan Nacional para el Buen Vivir 2013-2019”, Quito, Ecuador. Recuperado de $<$ http://www.buenvivir.gob.ec/>.

Serna, C. y Gómez, J. (2013). “Oficina virtual de catastro”, tesis de grado. Recuperado de <http://hdl.handle.net/10819/2120>.

Vázquez Asenjo, O.G. (2013). Coordinación ente el Catastro y el Registro de la Propiedad. Monografías. Ed. Tirant lo Blanch, 485.

Wang, F. (1994). "Towards a natural language user interface: An approach of fuzzy query”, International Journal of Geographical Information Systems, no. 8, pp. 143-162. 